\title{
The innovation of enterprise archives management practice based on the effective connection of information network
}

\author{
ZHANG Jixian
}

Weifang vocational college, Weifang, 261041, China.

Keywords: enterprise information; archives; management; innovation; network

\begin{abstract}
The enterprise is making great efforts to the development of information construction, archives management should according to the special function of archives information unique sexuality and archives management, conception and design to computer technology as the theme, is conducive to the special function of archives management and improve the information-based degree of enterprise archives management system and other information management system to effectively join the integrated management system. It should be from the working platform, process, management, systems and services in five aspects, explore new areas and methods of management, refining innovative management ideas, and innovation road of documents and archives management.
\end{abstract}

\section{Introduction}

Archives is the enterprise information management in the unique characteristics of files in the historical records of all enterprise production and management activities. In the enterprise information management has three differences with other management information unique sexuality. In 2002, Central Committee issued vigorously strengthen the construction of enterprise information management requirements, and propose specific targets, in order to promote the healthy development of the construction of enterprise information management, improve enterprise management level and market competitiveness. Enterprises vigorously implement the background of informatization construction in, documents and archives management practice ushered in the great opportunities for innovation and empty.

\section{Computer technology and network technology applied to the new requirements of file management}

Archives is the enterprise information management in the unique characteristics of files in the historical records of all enterprise production and management activities. In the enterprise information management has three differences with other management information unique sexuality. Original features. Enterprises in all historical periods in including production and management, product development, management strategy, application of science and technology, market sales and economic benefit of all economic activities, from the beginning stage is in form of archives shall be authentic, accurate and complete records and according to its value orientation, according to records centralized management principle, using traditional or modern style, both manual and computer operation of generation of archive. Enterprises provide guidelines, preservation and utilization, become subject to time and space constraints across time and space of the archives information resources, can provide realistic production and management decision-making, technical innovation, product development to provide the basis for the enterprise long-term development of business strategy, technology development and research activities to provide historical origin of demonstration data, also can do for the enterprise, the external law of letter of credit basis. Second memorandum characteristic. In the stage of scientific research projects, infrastructure projects and product upgrading of business activities, the file to the memo recording characteristics of each stage of the whole story and its running process, so that the file has become one of the operation process and the activity generated synchronously At the end of the discussion of how the products. From the file can understand the project started, start and end and in the process of success and failure of the 
reasons for the next stage to provide decision-making basis. Moreover, utilization of archives management technology making the text, digital audio and video, CD-ROM archives, becoming the stage, the whole process of important standards. In some extent, the file interface and complete degree can reflect the plan for implementation of the project quality and effect. Three is the preferred characteristics. The file management and information network in other information management system with the same information collection and processing, transmission, storage, development and utilization Basic function but archives management also has the screening of a difference with other information management, optimization function, the database of information network have important information long-term preservation value of the archives formation, composed of long-term or permanent save files, centralized and unified and standardized custody to the essence of enterprise information resource accumulation, to prepare for use.

Special function of archives management in the network information in the computer technology and network technology gradually applied in the file management, gradually by the operation of a computer application for the theme of modern archival management alternative to manual operation method of traditional archives management, archives management in enterprise information network operation with three different to other information management system of special features. Information extensions. Archives management has not only with other information management system on the same network information processing and communication function, but also has information function extension, namely on network conversion over the important information, in the use of document login technology well the archival filing, Method according to the professional standard copy under the control of a full-text information, retrieval service, at the same time, but also can be converted into archives information library, the archives retrieval implementation files, file level secondary questions, realize archives and documents, the text of the three stage shows, and to secure to use open. At the same time, also can have the file derivatives, such as information excerpts, thematic information collection, important information and historical reference, in order to ensure the information resources effective development and utilization. The second is the business functions. The file management department is the information management department, the archives information management standards are promulgated by the state $(<$ File $>$ regulations formed, with Statutory authority. Therefore, archives management into enterprise information network operation, can use file management of the business standards, to other information management system management, restriction and influence, make it from the starting point to run and archive management standard unity. Such as information and database, the formation of standard form and the original data bearing taken to ensure convergence of the archives management and information network system function. Third, the supervision and guidance functions. File management system in enterprise information network information stream processing, with the guidance and supervision of the authority in accordance with the law. Such as on the important management information collection and processing technology Supervision and management of the affiliated archives management institutions, professional archives in the authenticity of the information, the accuracy of the implementation of supervision; in the security and confidentiality of the corresponding management and control, to improve the level of information management.

Focus on the archives management and information network effective coupling idea according to the enactment of the national < Archives Law $>$ provisions, it should be from the archives management in the network information with unique characteristics and function, start from the strengthening of the modernization of enterprise information network, put forward reasonable and suitable effective coupling conception. One is built to archives management standards for elements of the business norms. The unity of archives management and information management business standards, is whether the two key connection. Therefore, in the enterprise information network management information subsystem formed electronic files of the soft and hard environment and appropriate conditions should be based on, using principle of file management technology and total quality management techniques, built Made from the information collected to the development and use of specific general information comprehensive management specification. Such as information 
acquisition, processing, processing, circulation, filing, copying, use and security standards, as well as the information formation department working system; information exchange between the various subsystems, conversion, announced measures for the implementation of; unified information of the subsystems of database, database setup information file format and incorporated into the enterprise standard for unified management assessment, standardization, the implementation of the system of information management standards, to ensure their effective connection and operation. The second is to establish archives management department for leading guidance system. On the basis of the national promulgation $<$ File $>$ conferred powers of supervision and guidance of the archives management department, set up to take charge of the principal leaders of enterprises, based on archives management department, to professional records management personnel as the backbone of the information management system to guide the, on various information management systems to implement technical guidance, implement information management practices, and to develop appropriate guidance system. Such as the establishment of enterprise leadership and management information responsibility system, the archives management department operational guidance range of responsibilities and professional management personnel post responsibility system, and enterprise information network system accept guidance system; establish $<$ information management business guide the record $>$ in network information subsystem, $<$ information management inspection and evaluation of anti Single feed $>$, and information management, analysis, assessment, evaluation, reward and punishment system, to guide the effective and timely service, improve quality of connection of the two. The third is to establish to the development and utilization of information as the focus of supervision mechanism. In the operation of enterprise information network system, the archives management department to exercise functions and powers of supervision according to law, and according to the $<$ File $>$ provisions, the preparation of the scope and methods for the supervision of major information development use. Development of supervisory system of job responsibility, to ensure the normal operation of the monitoring mechanism. Such as on science and technology, engineering, financial and other special archives management department, the implementation of standardized operation of supervision, to ensure that the original character of the electronic files, source And can not be changed; the important information to determine the file classification and publicly announced opportunity and condition monitoring, implementation of the security system; timely intervention in appraisal of achievements in scientific research, engineering construction and acceptance stage, equipment unpacking inspection and audio-visual production process, the operation quality of supervision and data collection and filing, with authority to supervise the implementation of promoting the modernization of information network.

\section{Innovative work platform}

To improve the international competitiveness of enterprises, according to the function of the enterprises to speed up the informationization construction pace. In construction or have been put into operation, undertake a wide variety of business functions and business activities of information management system, reflects the enterprise informationization construction achievement. To establish the information system of the traditional business flow optimization, software programming and database management technology, reshaping the computer workflow support, implementation and management mechanism function of business activities. These information systems are the source of enterprise electronic document center. Office automation system, such as administrative office areas to create log data, the processing cycle, archiving, identification, storage, transfer, use new job Platform. It relates to a lot of information, participation in numerous applications for the position; treatment process is complicated and changeable, the powerful database, fast transmission of information, easy to communicate; characteristics of information flow, office work flow is very close. Is more important, information system established the organization's business activities to provide a flow of information specification, centralized control, different form customization, flexible use of information platform, archives management practice to set foot on a new level. 


\section{Technological innovation}

As part of the work, work, work steps, documents and archives management more attention to specific business activities, management activities as a serial node forwarding process directly limit the process. Traditional serial working flow pattern formation affects the efficiency is a important factor. Information era and create a document integration process become new ideas, document integration process is determined in the information management system, documents and archives management process reengineering, BPR. In the information management system, business flow and information flow is integral, the file operation mechanism of visual information is the most important information flow, but also reflects the agency's business processes. Means that form the business processes at the same time, also documented and transferred to the target document integration process. It means information system meet the needs of business management, must also meet the requirements of documents and archives management. In the system to establish the new workflow, we can linked to a node in the process, to any task, can be any node as a starting point for radiation, closed loop, branch, sent to multiple objects. Process reengineering is improvement process of parallel degree and cooperation task processing, in order to improve the operational efficiency, realize the cooperation target, improve the quality of file.

\section{System innovation}

Ensure information system in the application process, can adapt to the different stages and the needs of users of different nature play a maximum efficiency, how to regulate the application, developing information system, in order to obtain the best results is enterprises to provide good management policy. In the era of information, documents and archives management system construction and office business management and information management are inseparable. Considering the specification and application of information system assurance, rational development, information security, enterprises need the management rules and regulations, standardize business, technical rules, organization and information department, business department along with the establishment of the common enterprise standards for enterprise information management system System. The work of the author's company, application in each stage of the office automation system has been established or are establishing systems: 1) < office automation system pull (oak) applications and operating maintenance procedures. The contents of the documents and archives management department, information management department of the division of labor; confirmed the identity of the information system, user rights management, management of user information changes, employee information management. B) < electronic document management method. Content is guidance of an electronic document management process, the use and management of electronic seal, electronic file transfer program and document information management, electronic paper application procedures and management. C) $<$ oak electronic document management rules . mainly used for archiving of electronic document metadata format required to fill in the contents of D) $<$ filing, sorting rules. Define the filing of electronic files of finishing, combing the integration process of IDCs) $<$ information system operation maintenance management method $\mathrm{f}$ ) $<$ information system operation safety management method only $<$ information system application training in business management method, and program. The correct information system, standardized operation and established.

\section{Service innovation}

File information and archival work service, content, and the traditional archives service utilization compared to the great changes, provides an unprecedented space for development and innovation. Innovation, i.e. to establish the concept of information service. Information system in-depth and extensive application, the formation of the large number of high quality of electronic file information resources. More information system user group information service requirements more and more widely. Therefore, the archives working personnel first established information 
service concept, service information emphasizes active. Archives of information sources, information sharing needs to be highly sensitive, often use their brains to think of ways to collect information. Survey information in understanding the needs of potential users, plan, design different levels of service content and scope, form, plan of electronic file information resources development, processing, conversion, made product information, provide services. In the service information providing, on the one hand, give full consideration to the needs of the user information, providing information to the user using the platform. General information application system, function module design, documents and archives management work to consider more comprehensive function, but the user's information, and often only to find the file itself, they expect to shorten the distance between the acquisition channels and humanized service use efficiency in the use of information and information quasi The formation of letters based on sharing accuracy. Therefore, it is necessary for the user to set up a special information platform, information filtering out some of the archives management attributes, the user a simple and quick access to the required information for the user's information platform, highlight the user's rights and interests, the protection of user information, user information and archives work experience, active users and archives work, on the other hand, the information needs to conduct a comprehensive investigation, the establishment of special collection, screening, deep processing of related information, with advanced technology as the foundation, will be a special CD - ROM information, product information, for the enterprise leaders and Industry Service departments to provide information service; the third is for remote user information needs to provide cross space, time, information services. Business department established information system, the problems are information data accumulated for a long time. How the science of custody, use them to become builders will have not considered the issue, and Archives Management Department has enough experience to solve these problems. Therefore information system construction units to provide data and information solutions is a higher level, a higher level of information service.

\section{Conclusion}

Information age brings us too many opportunities. Documents and archives workers must take the initiative to master the time rhythm, in documents and archives management practice, and actively explore new management method, distillation of management philosophy, get rid of confusion, make the file work and enterprise of hair development and innovation to keep pace, enables the individual's effort and enterprise to provide resources to create synergy, continuously improve the contents of science and technology in the archives management work, to find a new road to entrepreneurship.

\section{Reference}

[1] Feng Huiling. To expand the functions of - "the crevice time" of archival profession survival strategy [a]. The social memory of the 21 st century, China first archives science dissertation for the Doctoral Forum [C]. Beijing: China Renmin University Press, 2001.105 - 112.

[2] Feng Huiling. Electronic document management tutorial [M]. Beijing: China archives press, 2001 (in Chinese).

[3] li-min xie. ।"--।" half a century in our country history back and thinking [j]. Journal of jimei university, 2005 (3).

[4] wang yh, Daniel huang. The interests of the elementary education reform subject and its analysis [j]. Journal of contemporary education science, 2006 (4).

[5] Wang Rongqin. Learning difficulties the psychological barriers and its transformation of the underachiever strategies [J], 2001.

[6] Li Kexin, min. The theory of difference of the concept, origin and education measures [J] journal of yantai teachers college (zhe edition), 1998, 2. 